ISSN: 1641-4713; e-ISSN: 2081-1160

DOI: https://doi.org/10.36551/2081-1160.2021.28.179-204

\title{
Paraguay, exilio masivo y retorno selectivo
}

Paraguay, massive exile and partial return

\section{Luis Roniger}

Universidad Wake Forest, Estados Unidos

ORCID iD: https://orcid.org/0000-0002-0246-5384

E-mail: ronigerl@wfu.edu

Leonardo Senkman

Universidad Hebrea de Jerusalén, Israel

ORCID iD: https://orcid.org/0000-0002-4799-2524

E-mail: leonardo.senkman@mail.huji.ac.il

Saúl Sosnowski

Universidad de Maryland, Estados Unidos

ORCID iD: https://orcid.org/0000-0003-0096-8620

E-mail: sosnowsk@umd.edu

Mario Sznajder

Universidad Hebrea de Jerusalén, Israel

ORCID iD: https://orcid.org/0000-0002-0829-3480

E-mail: mario.sznajder@mail.huji.ac.il

Recepción: 24.04.2021

Aprobación: 29.12.2021

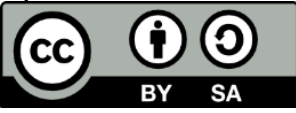

Resumen: La larga dictadura de Alfredo Stroessner (1954-1989) generó un éxodo sostenido de paraguayos que huyeron de su país y se sumaron a las comunidades de la diáspora ya existentes desde el siglo XIX, particularmente en la Argentina. Este artículo, basado en parte en una investigación sobre exilio, diáspora y retorno en el Cono Sur que incluye el caso paraguayo y que publicará Eudeba, la Editorial Universitaria de Buenos Aires, intenta aproximarse al tema del exilio masivo de paraguayos y su retorno selectivo. En las páginas siguientes, enfocaremos el proceso de desplazamiento masivo fuera del territorio nacional, su radicación principalmente en los países limítrofes, la movilización de la diáspora paraguaya y cerraremos con un análisis del proceso parcial de 
retorno. Tal desplazamiento refleja la amplia exclusión de sectores políticos y sociales que generaba el régimen autoritario, ya fuere una exclusión predominantemente socioeconómica, como en el caso de los migrantes, o bien político-institucional, como en el caso de los deportados y fugitivos que partían al exilio. Nuestro análisis se basa en forma especial en entrevistas llevadas a cabo por los autores en Paraguay entre 2010-2012, cuyos testimonios permiten evaluar las perspectivas del desexilio y el impacto de los retornados, antes y después del fin de la dictadura.

Palabras clave: destierro, diáspora, movilización y resistencia, retorno y desexilio, impactos políticos y culturales

Abstract: This article analyzes the process of massive displacement of Paraguayans outside the national territory, their settlement mainly in the neighboring countries, the mobilization of the diaspora, and the partial process of return. Recognizing its roots in the nineteenth century, it focuses analysis on the waves of forced displacement and migration generated under during the authoritarian regime of General Alfredo Stroessner (1954-1989), which reflected the exclusion of wide political and social sectors. The analysis integrates the testimonies of key political and cultural figures who experienced exile, based on interviews carried out by the authors in Paraguay between 20102012, bringing up former migrants and exiles' perspectives on the experiences of exile and return before and after the end of the dictatorship.

Keywords: territorial displacement, diaspora, mobilization and resistance, return dynamics, political and cultural impacts

\section{LA DIÁSPORA PARAGUAYA: DEPORTADOS, FUGITIVOS, EXILIADOS, MIGRANTES}

Durante la Guerra Fría, la diáspora paraguaya fue una de las mayores de Sudamérica. Sus orígenes se remontan al siglo XIX. Desde el final de la Guerra del Paraguay (1864-1870), muchos emigraron en busca de empleo y otros fueron deportados o huyeron para escapar persecución. El flujo de exiliados y migrantes se dio tanto en períodos de gran inestabilidad (por ejemplo, el período 1904-1922 con 15 presidentes, o durante guerras civiles, como a principios de la década de 1920 y en 1947) como en períodos de concentración de poder y represión, por ejemplo, en 1940-1946 y bajo Stroessner.

La caída del poder implicaba deportación, fuga y exilio. En 1936, muchos miembros y simpatizantes del Partido Liberal contrarios al gobierno del Coronel Rafael Franco debieron huir al exilio. Cuando finalmente lograron deponerlo en agosto de 1937, Franco y muchos de sus partidarios partieron al exilio. Entre ellos, el ministro Juan Stefanich y Elpidio Yegros, expresidente en funciones de la ANEC, una asociación de veteranos de la Guerra del Chaco (1932-35) que contaba con unos 106000 miembros. Todo intento de insurrección fue seguido de represión y nuevos exilios que llevaron finalmente al ascenso de Alfredo Stroessner al poder absoluto. Cuando el presidente Estigarribia murió en un 
accidente aéreo en septiembre de 1940, los llamados Nuevos Liberales debieron exiliarse o enfrentar la cárcel, una vez que otros oficiales y una facción de Liberales más conservadores tomaron el poder y eligieron al ex ministro de defensa Higinio Morínigo como presidente. Poco después, Moríñigo deportó a otros coroneles del ejército quienes, a pesar de haber apoyado su ascenso al poder, fueron considerados conspiradores. También proscribió al Partido Liberal en 1942, y la mayoría de los políticos Liberales se exiliaron, junto con activistas estudiantiles que conspiraron a favor del retorno del Coronel Franco al poder. En las postrimerías de la Segunda Guerra Mundial, Morínigo también expulsó a una facción profascista de oficiales, que hasta entonces había sido influyente. Cuando en 1946 los integrantes de ese grupo intentaron llevar a cabo un golpe de estado, fueron deportados. Incluso Alfredo Stroessner se asiló en la embajada de Brasil después de un fallido golpe de estado en 1948. El poder del Partido Colorado -oficialmente: la Alianza Nacional Republicana, ANR - superó a los Liberales que habían sido la fuerza predominante desde el fin de la Guerra de la Triple Alianza. Cuando los Colorados lanzaron una campaña de terror contra la oposición y algunos sectores internos, muchos huyeron a la Argentina.

En 1954 Alfredo Stroessner ocupó el poder y rápidamente se impuso al Partido Colorado y a las fuerzas armadas, exiliando a su vez a políticos independientes y deshaciéndose de cualquiera que tuviera aspiraciones políticas o bases de poder propias. Bajo Stroessner miles de paraguayos fueron presos, torturados, desaparecidos o desterrados. Su designio era sembrar el miedo y disuadir a la gente de toda crítica al gobierno; las persecuciones estaban tan extendidas que en cada manzana de la ciudad se podía encontrar a alguien que había sido encarcelado o torturado (B. Fernández Bogado, ${ }^{1}$ comunicación personal, 9 de abril de 2010). Bernardino Cano Radil, ${ }^{2}$ quien de niño partió a Córdoba (Argentina) con su familia afiliada al Partido Colorado, consideró el estilo represivo de la dictadura "más primitivo" que los de Argentina, Chile y Uruguay. Stroessner, dijo, seguía el modelo de los dictadores caudillistas, "peor que Perón, pero mejor que Batista de Cuba" (B. Cano Radil, comunicación personal, 13 de abril de 2010). Como señaló José Carlos Rodríguez, ${ }^{3}$ el hecho de tener un amigo 'subversivo' bastaba para calificar a una persona de la misma manera; según él, unos 20.000 paraguayos fueron torturados (J. Carlos Rodríguez, comunicación personal, 11 de abril de 2010 y 28 de agosto de 2012).

\footnotetext{
${ }^{1}$ Director de Radio Libre y uno de los redactores de la Constitución de 1992.

${ }^{2}$ Líder del ala democrática del partido Colorado y exvicepresidente de la Cámara de Diputados.

${ }^{3}$ Entonces investigador del Centro de Documentación y Estudios (CDE).
} 
Asimismo, Stroessner mantenía una política de cooperación con las otras dictaduras latinoamericanas, lo cual le permitió infiltrarse en las comunidades de exiliados, impedir el retorno de opositores o interrogarlos y torturarlos a su regreso. Los casos de Martín Almada y Félix de Guarania son ilustrativos. Tras graduarse en la Universidad Nacional de La Plata (Argentina) en 1974 con un doctorado en política educativa en el que siguió a Paulo Freire y los teóricos de la dependencia, Martín Almada regresó a Asunción y fue detenido, ya que era activista sindical y su tesis doctoral fue calificada de "subversiva". Afirmó haber sido interrogado por hombres vestidos de civil en quienes reconocía su acento argentino y chileno. Después de un mes de prisión y de padecer torturas, fue liberado sin que supiera qué buscaban sus captores (M. Almada, comunicación personal, 11 de abril de 2010). Félix de Guarania relató en nuestra entrevista que a su regreso a Buenos Aires en 1975 fue detenido por las fuerzas de seguridad argentinas y que decenas de paraguayos fueron secuestrados y muchos desaparecieron bajo el accionar coordinado de las fuerzas transfronterizas de las dictaduras que, entre otras acciones, también intercambiaban prisioneros (F. de Guarania, comunicación personal, 13 de abril de 2010).

Entre los exiliados más notorios estaban Eusebio Ayala; Rafael Franco; Carlos Pastore Goiburú; Waldino Ramón Lovera; los escritores Augusto Roa Bastos, Rubén Bareiro Saguier, Carmen Soler y Gabriel Casaccia; los músicos José Asunción Flores, Epifanio Méndez Fleitas (que había sido presidente del Banco Central en 1952-1955) y Teodoro Salvador Mongelós. Muchos no volverían, como el expresidente de la Corte Suprema de Justicia Pedro Samaniego, quien murió en el exilio; o regresarían solo después de largos años en el exterior, como ocurrió con Augusto Roa Bastos y Rubén Bareiro Saguier.

Incluso después de la caída del gobierno de Stroessner en 1989, el destierro continuó siendo el destino posible de quienes perdieran el poder. Tal fue el caso de Raúl Cubas Grau, presidente electo en 1998, quien, ante las acusaciones de estar implicado en el asesinato del vicepresidente Luis María Argaña, disturbios masivos y un posible juicio político, renunció y huyó a Brasil en marzo de 1999. Otra figura prominente implicada en el asesinato, el General Lino Oviedo, huyó a Argentina y regresó más tarde para dirigir una importante fuerza política.

Una característica importante de la diáspora paraguaya fue su mayor concentración en Argentina, seguida de otras menores en Uruguay, Brasil y España. Decenas de miles de exiliados se trasladaron sobre todo a la vecina Argentina, donde también se había asentado un gran número de trabajadores migrantes paraguayos, especialmente en Buenos Aires y Posadas. La porosa frontera posibilitó la movilidad y el cruce de jurisdicciones. En efecto, muchos paraguayos se radicaron 
en Buenos Aires y en las provincias de Formosa, Corrientes y Entre Ríos. Desde allí, cerca de su país, lideraron una doble militancia. Participaron en sindicatos, grupos políticos, universidades, lugares de trabajo y vecindarios argentinos, incluidos los barrios populares y las 'villas miseria', y, al mismo tiempo, se dedicaron activamente a organizar redes de paraguayos opositores con miras a derrocar a Stroessner. En general, los exiliados paraguayos en la diáspora permanecieron activos políticamente, pero se enfrentaron a pérdidas, decepciones y desolación. Stroessner no cayó como resultado de protestas ni por la insurgencia armada. Al concederse amnistías, algunos exiliados retornaban al Paraguay para verse forzados a partir nuevamente tras otras olas represivas. Para unos pocos, el retorno se materializó sólo a fines de la década de 1980 y especialmente una vez que la dictadura llegó a su fin.

\section{MOVILIZACIÓN Y RESISTENCIA EN EL DESTIERRO}

Los Febreristas fueron uno de los grupos más grandes en el exilio. Prófugos desde 1937, aquellos exiliados eligieron una estrategia de subversión contra el gobierno al que consideraban ilegítimo. Sin embargo, su dispersión entre Asunción, Argentina y Montevideo supuso serios problemas de coordinación que jugaron a favor de Stroessner. La resistencia Febrerista fuera del Paraguay fue más fuerte que la escasa resistencia clandestina dentro del país. Las acciones principales de la oposición tomaron la forma de incursiones guerrilleras, pero éstas fracasaron al haber sido infiltradas por informantes. Además, tales acciones no fueron bienvenidas dentro del Paraguay, ya que los opositores locales afirmaron ser 'los más afectados por las represalias del gobierno' de Stroessner (Lewis, 1968, pp. 113-114). Mientras la población rural no se sumaba a la insurrección, sectarismos y divisiones minaron al Febrerismo e impidieron que retomara el poder. El Partido Liberal fue legalizado nuevamente en 1967, pero los Febreristas habrían de soportar un exilio mucho más prolongado.

Por otra parte, los miembros del Movimiento Popular Colorado, MOPOCO, que rompieron con el partido Colorado, debieron exiliarse tras un fracasado intento de derrocar a Stroessner. Probablemente la personalidad más conocida de sus filas fue Agustín Goibirú, el líder que había sido expulsado en 1959 junto con otros compañeros por haber criticado las políticas represivas del régimen. Goibirú fue "marcado" por el régimen después de haber planeado y fracasado en un intento de tomar una aeronave paraguaya en Encarnación, al otro lado de la frontera de su ciudad argentina de exilio, y volar a una reunión de ministros latinoamericanos de Relaciones Exteriores en Punta del Este, Uruguay. Al regre- 
sar a Argentina, mientras ejercía la medicina, Goibirú siguió promoviendo la oposición a Stroessner. En 1969 fue secuestrado en Argentina y trasladado a una cárcel en Paraguay, de donde logró huir al año siguiente. En 1974, Goibirú y miembros de MOPOCO habían planeado asesinar a Stroessner, pero fracasaron. Desde entonces, Goibirú fue espiado y vigilado. En febrero de 1977 fue secuestrado por segunda vez y asesinado en Paraguay (Boccia Paz, 2014).

La convicción de que la lucha armada podría poner fin al poder autoritario de Stroessner se vio avalada por la cantidad de complots y golpes de estado, muchos de ellos exitosos, por parte de diversos sectores de las fuerzas armadas, y fortalecida por la relativa cercanía de la capital paraguaya a Argentina. Durante la larga dictadura, hubo varios grupos de exiliados dispuestos a retornar y liderar la lucha armada. Tal fue el caso del 'Movimiento 14 de Mayo para la Liberación del Paraguay' (M14), un grupo guerrillero integrado por Liberales y Febreristas radicados en la Argentina. Dados los estrechos vínculos entre el General Stroessner y el depuesto General Perón, el M14 contaba con el apoyo del gobierno antiperonista argentino que lo derrocó en 1955. Cinco columnas de guerrilleros armados intentaron infiltrarse en Paraguay a través de la frontera argentina en diciembre de 1959. La mayoría de ellos fue detectada, pero algunos lograron penetrar unos 100 a 200 kilómetros en territorio paraguayo. Las columnas llevaban consigo una radio clandestina tanto para comunicarse como para difundir propaganda. En dos semanas, todos los grupos excepto uno fueron capturados. El grupo restante, encabezado por Juan José Rotella, supo del fracaso de las otras columnas y se replegó a la Argentina. En abril de 1960 el grupo ingresó nuevamente al Paraguay, pero todos sus miembros fueron capturados y ejecutados. Los integrantes de los otros cuatro grupos habían sido encarcelados en Peña Hermosa, un campamento militar de la armada y el ejército paraguayos en el norte, cerca de la frontera con Brasil. Los prisioneros escaparon a fines de abril de 1961 y regresaron individualmente al Paraguay al finalizar la dictadura. El fracaso de las acciones guerrilleras no destruyó por completo la resistencia, pero disminuyó drásticamente el apoyo político a la lucha armada, en tanto que le permitió a Stroessner autentificar su narrativa de hallarse en guerra contra la subversión (Arellano, 2004).

Probablemente el intento más serio de insurgencia contra Stroessner fue llevado a cabo entre 1974 y 1976 por la Organización Político Militar. La OPM surgió cuando Juan Carlos da Costa, un preso excarcelado, llegó como exiliado a Chile, donde entró en contacto con jóvenes estudiantes paraguayos testigos de las movilizaciones populares durante el gobierno de Salvador Allende. Tras el golpe del 11 de septiembre de 1973, escaparon a la Argentina y crearon una red clandestina conectada con grupos opositores en Paraguay, que incluían a estu- 
diantes, obreros y las ligas campesinas cristianas en zonas rurales. Cuando Stroessner se apoderó de todo el archivo de la OPM, a partir de confesiones obtenidas bajo tortura, en 1976 llevó a cabo una de las operaciones represivas más duras. Esto produjo una fuga masiva de partidarios y simpatizantes urbanos y rurales de la OPM, principalmente hacia la Argentina (Boccia Paz, 1997, 2004b). Pensaron coordinar acciones con grupos argentinos como los Montoneros y el Ejército Popular Revolucionario Trotskista (ERP), el Ejército de Liberación Nacional Boliviano (ELN) y el Movimiento de Izquierda Revolucionaria de Chile (MIR). Su plan era provocar una insurrección popular o una victoria guerrillera en algún país del Cono Sur. La coordinación de los servicios de contrainteligencia y las operaciones transfronterizas conjuntas de la Operación Cóndor fueron decisivas al desarticular a la OPM y a los otros grupos guerrilleros en la región (Dinges, 2005; Roniger, 2010).

En 1976, Argentina -el último país del Cono Sur en caer en dictadurase convirtió en una trampa para los exiliados paraguayos que tenían un historial de activismo contra Stroessner o que estaban involucrados en la política y en los sindicatos argentinos. Un caso típico fue el de Federico Tatter Moríñigo que se había exiliado en Argentina de 1947 a 1950, fecha en que pasó a Uruguay. En 1952 pudo regresar a Paraguay y permanecer hasta 1963, cuando su activismo político lo llevó nuevamente al exilio. En octubre de 1976, fue secuestrado y desaparecido en Argentina. Su esposa Ida se unió a otras mujeres con el mismo drama y fundó la Comisión de Paraguayos Detenidos Desaparecidos. Las mujeres paraguayas cuyos familiares se contaban entre los desaparecidos también participaron activamente en la organización de las Madres de Plaza de Mayo. Esther Ballestrino de Careaga, bioquímica y farmacéutica activa en el movimiento Febrerista, reconocida por el ACNUR como refugiada, y que iba a asilarse en Europa, fue secuestrada en diciembre de 1977 al unirse a las Madres tras el arresto de su hija. Desapareció junto a otras dos madres, Ramona Cattoni y María Gastón. María Antonia Sánchez señaló a las mujeres paraguayas que eran líderes activistas, algunas de las cuales fueron asesinadas. Una de las tres líderes de la OPM fue Nidia González Talavera, que logró escapar en 1976 y pasó a la clandestinidad en Argentina. Otra fue Guillermina Kanonnikoff, esposa de Mario Schaerer Prono, un destacado activista herido y muerto bajo tortura (Sánchez, 2011).

La actividad de las organizaciones culturales en el exilio fue importantísima. Los conciertos de artistas exiliados, las numerosas publicaciones y los eventos sociales y deportivos de la diáspora paraguaya preservaron su identidad nacional y lingüística, y al mismo tiempo mantuvieron un activismo político que buscaba poner fin a la dictadura y posibilitar el eventual retorno al territorio patrio. Los 
programas de radio y televisión y las publicaciones comunitarias también desempeñaron un papel crucial, en particular entre quienes seguían en un exilio prolongado.

El Partido Febrerista del Paraguay cooperó en un Comité coordinador de fuerzas democráticas del Cono Sur que articuló las actividades de denuncia de las dictaduras del Cono Sur. Asimismo, aprovechando los vínculos con otras organizaciones, los exiliados latinoamericanos crearon FEDEFAM (Federación de asociaciones latinoamericanas de familiares de desaparecidos), compuesta por cinco asociaciones paraguayas, además de asociaciones de Argentina, Chile, Uruguay, Colombia, Bolivia, Brasil, Honduras y México. Ello fue parte de un trabajo aún más amplio de organizarse a nivel regional para ayudar a quienes requerían asilo o amparo a través de contactos con las redes de derechos humanos, religiosas y de exiliados de todo el mundo (Ayala, 2014).

Hasta el fin de la Guerra Fría, Stroessner jugó la carta de estar en la primera línea de la defensa occidental contra el comunismo y mantuvo una fachada democrática, sustentada por partidos políticos y elecciones. Ello dificultaba que los exiliados impactaran la opinión pública mundial, además la insularidad de Paraguay que, al carecer de una salida directa al mar y con la gran mayoría de la diáspora concentrada en Argentina, no estaba abierto al mundo.

\section{EL ENTORNO REGIONAL DE CAMBIO Y SUS EFECTOS}

El retorno del destierro comenzó bajo la dictadura, supeditado a los mandatos de Stroessner, sobre todo tras el retorno de la democracia en Argentina. Ello contrasta con el caso de los desterrados argentinos y uruguayos, que en su mayoría fue un fenómeno postdictatorial.

Con la caída del régimen militar en Argentina en diciembre de 1983, la situación de la oposición paraguaya en el exilio cambió radicalmente. Consciente del peligro de tener a la oposición en una Argentina democrática, Stroessner decidió permitir el regreso de los exiliados. La libertad de expresión en el país vecino daría nueva voz a la oposición, compuesta por activistas políticos de una larga lista de organizaciones que abarcaba desde los Liberales hasta el Movimiento Marxista Patria Libre (MPL). Al permitir el retorno, Stroessner esperaba evitar que la oposición lograra centralizar el tema de Paraguay en la opinión pública argentina, lo cual podría afectar el inicio de las obras de la represa binacional de Yacyretá, un emprendimiento económico de 10000 millones de dólares, que estaba a punto de comenzar ese mes de diciembre de 1983.

Stroessner consintió entonces que los exiliados regresaran al Paraguay, donde sus fuerzas de seguridad podrían controlarlos. El regreso tenía que efectu- 
arse según notificaciones individuales de fecha y lugar de llegada. Se permitió el regreso de los desterrados, con la excepción de Domingo Laíno y Luis Alfonso Resck, considerados líderes subversivos. Bajo el liderazgo de Laíno, exiliado desde 1982, los partidos de la oposición -el Partido Liberal Radical Auténtico, el Partido Demócrata Cristiano, el MOPOCO y los Febreristas- habían logrado coordinar sus acciones ("Crónica sobre el retorno", 1984; Moyas Cobos, 1989). $\mathrm{Si}$ bien denunciaron las condiciones impuestas para retornar (lo que denominaron de "falsa apertura"), todos los partidos de oposición apoyaron el regreso con vistas a continuar la lucha dentro del país. Por un lado, los exiliados interpretaban el cambio de política como consecuencia de las crisis internas, que afectaban la capacidad del régimen de seguir sometiendo a la población, pero a la vez reivindicaban para sí mismos un protagonismo político en el nuevo contexto regional (Moyas Cobos, 1984, 1989).

Uno de los documentos más importantes de las figuras estelares del exilio fue la "Carta abierta' al pueblo paraguayo", firmada por Augusto Roa Bastos en Toulouse el 1 de febrero de 1986, en ocasión del 50 aniversario del fin de la Guerra del Chaco, en la que había luchado. En ella, el destacado escritor subrayó la necesidad de lograr que la dictadura concluyera sin necesidad de violencia y planteó una serie de puntos concretos. En la carta destacaba que el destierro privilegió su voz crítica fuera de la patria:

He atacado sin tregua [a Stroessner, jefe de gobierno] en cuyas manos se halla concen-
trado el poder autoritario unipersonal que desde hace más de treinta años rige los destinos
del país al arbitrio de su sola y omnímoda voluntad. ... En el exilio interno mi voz se
habría sumado de seguro a la forzosa y forzada mudez general. Al serme infligido, como
a otros incontables compatriotas, el exilio perpetuo - que yo no experimenté jamás como
una sanción revocatoria de mi condición de ciudadano, sino como única distinción que
podía recibir de un régimen semejante-, éste me otorgó sin quererlo la facultad de
combatirlo en igualdad de condiciones. En el centro del poder que le vuelve inapelable,
y tal vez sordo, salvo a la adulonería, su jefe puede ser interpelado por cualquiera, en
libertad y dignidad, desde el centro del exilio que es el contrapoder de los perseguidos.
(Roa Bastos, 1986)

En efecto, según el testimonio de Antonio Pecci, Roa Bastos había jugado un rol fundamental en la campaña contra Stroessner, sobre todo después de 1982, cuando participó en un gran encuentro internacional en febrero de 1987 en Madrid, bajo los auspicios del Partido Socialista Obrero Español (PSOE). Fue en ese encuentro, al cual concurrieron unas 40 figuras de distinta afiliación política, algunas procedentes de distintos sitios de exilio y otras residentes del Paraguay, donde Roa Bastos lanzó un llamado a promover la democracia sin recurrir a la violencia, en un momento en el que muchos temían la guerra civil (A. Pecci, comunicación personal, 30 de agosto de 2012). Como reacción, la dictadura revocó 
la ciudadanía de Roa Bastos, pero luego el escritor recibió una ciudadanía española honoraria en 1983 y una ciudadanía francesa en 1987.

Pecci publicó una serie de entrevistas con Roa Bastos en la prensa local, más tarde reunidas en Roa Bastos: vida, obra y pensamiento, un libro que también incluye las voces de tres escritores paraguayos y tres argentinos sobre la vida y obra de esa figura central de las letras paraguayas (Pecci, 1997). En un diálogo que mantuvo con nosotros, Pecci recordó que, a pesar del reconocimiento internacional del que gozaba Roa Bastos, nunca se le ofreció un cargo formal. El Partido Colorado, que controlaba la Universidad Nacional, lo veía con recelo, y la Universidad Católica "Nuestra Señora de la Asunción" temía su postura izquierdista y lo consideraba inadecuado ya que estaba divorciado. Paradójicamente, fue el General Andrés Rodríguez, el militar y consuegro que derrocó a Stroessner, quien le otorgó un importante premio.

Desde el ámbito de la cultura, Roa Bastos deseaba contribuir a la reunificación pacífica de la ciudadanía. Aun así, la carta de 1986 puede ser leída como un valioso documento político ya que se adentra en propuestas específicas que esperaba que Stroessner llevara a cabo antes de renunciar a la presidencia. Enumeraba trece puntos, entre ellos un llamamiento a la amnistía incondicional para todos los presos políticos, así como el regreso de los exiliados sin exclusiones y con plenas garantías de ejercer sus derechos y disfrutar de legítimas libertades ciudadanas. En cuanto a la necesaria reorganización institucional, hizo un llamado a la Iglesia y a las Fuerzas Armadas a que cumplieran con su mandato profesional, desprovisto de sesgos políticos, una vez restaurada la democracia. Roa Bastos esperaba que el desarrollo cultural jugara un papel estabilizador y promoviera el pluralismo democrático; creía que los 'trabajadores de la cultura' pueden y deben servir como catalizadores para promover la agenda política.

\section{EL DERROCAMIENTO DE STROESSNER Y LA REPATRIACIÓN}

Stroessner logró permanecer en el poder controlando posiciones y las bases de apoyo al régimen, infiltrando a la oposición externa y eliminando toda oposición interna con represión férrea, promoviendo al mismo tiempo el culto a su personalidad. Sólo en 1989, una escisión en el círculo cercano al dictador lo obligó a dejar el poder y lo llevó a exiliarse en Brasil, donde murió en 2006.

Dado el carácter del derrocamiento de Stroessner por fuerzas cercanas al dictador, la transición paraguaya no implicó una ruptura con el pasado. El temario de la justicia transicional fue dejado de lado en parte por la magnitud abrumadora de la represión generalizada y la carga dolorosa del pasado. Solo gradualmente 
se discutió la complicidad de amplios sectores sociales con el régimen de Stroessner, pero aun así más en términos de imputar culpas que de reconocer el consentimiento tácito o la propia participación.

Tras décadas de adoctrinamiento, el rechazo de quienes regresaban del exilio no constituyó un incidente aislado y se manifestó sobre todo en el plano político. Con ello, la transición democrática de Paraguay y la debacle económica argentina de 2001 produjeron un importante flujo de retornados, que incluía a hijas e hijos de quienes habían abandonado el país años atrás. A nivel organizativo, en 1989 el nuevo gobierno creó el Consejo Nacional de Repatriación de Connacionales de Paraguay, rebautizado en 1993 con el nombre de Secretaría de Desarrollo para Repatriados y Refugiados Connacionales, una agencia estatal que registraba a los retornados potenciales, les proporcionaban información y coordinaban la asistencia administrativa en oficinas públicas, incluyendo asuntos relacionados con la vivienda, la salud y el empleo. Los hijos y las hijas de paraguayos que regresaban gozaban de una consideración especial en cuanto a residencia, ciudadanía, acceso a empleo y servicios de salud pública (E. S. Lugo Gaona, comunicación personal, 13 de abril de 2010; Souchaud, 2010).

El derrocamiento de Stroessner abrió la posibilidad de un retorno amplio. Muchas fuerzas políticas habían sido expulsadas o forzadas a huir, e incluso el Partido Colorado, que constituía la columna vertebral de la reivindicación de legitimidad y poder de Stroessner, tenía gran número de activistas y simpatizantes exiliados en Argentina. Según sus publicaciones, la Secretaría de Desarrollo para Repatriados y Refugiados Connacionales buscaba reincorporar y promover la inclusión de los retornados. Consideraba al Paraguay como "una nación históricamente migrante", y apoyaba iniciativas tendientes a establecer la continuidad y el fortalecimiento de las relaciones con el país. Consideraba su misión "colocar en igualdad de condiciones a los retornantes y los residentes, potenciando la relación entre uno y otro en pro del desarrollo nacional, teniendo presente el hecho de que el intercambio entre la expatriación y la repatriación trae consigo ventajas sociales". De ello derivaba atender a los retornados, y establecer vínculos con los paraguayos en el extranjero que mantenían interés en el país de origen y/o pensaran regresar. Entre sus funciones específicas, el sitio web de la Secretaría indicaba que había establecido contactos y mecanismos específicos mediante la emisión de certificados de repatriación gratuitos, y el procedimiento para el trato de los retornados y sus familias en las diversas agencias estatales. A través de dependencias regionales, quienes obtuvieran un certificado podrían optar, entre otros beneficios, por el patrocinio profesional gratuito para obtener la nacionalidad paraguaya para niños nacidos en el extranjero, tramitar la revalidación de diplomas 
y recibir ayuda humanitaria en el caso de personas en situación de riesgo, así como la exención de impuestos aduaneros (Secretaría de Desarrollo Para Repatriados y Refugiados Connacionales, s.f.).

Sin embargo, los repatriados con quienes conversamos indicaron que, si bien conocían la existencia de la agencia estatal, muchos no acudieron a ella ni encontraban sus servicios eficientes, por lo cual optaban por el contacto directo con círculos profesionales y familiares para emprender el retorno y reubicarse en el país. Las formalidades implementadas, según éstos, no respondían en forma adecuada a las necesidades de quienes regresaban, pero les permitían obtener documentos en forma legal.

\section{EL ROL DE LOS RETORNADOS EN LA APERTURA DEMOCRÁTICA}

Algunos retornados contribuyeron enormemente a promover una mayor conciencia democrática. Destaquemos la trayectoria de algunos de ellos: Bernardino Cano Radil y Rubén Bareiro Saguier participaron en la redacción de una nueva constitución. José Carlos Rodríguez dirigió la Comisión de la Verdad y la Reconciliación de Paraguay. Martín Almada utilizó la nueva figura legal de habeas data y descubrió los Archivos del Terror, un hecho que tuvo impacto transnacional ya que documentó información de la Operación Cóndor. El médico Alfredo Boccia Paz emprendió la publicación de artículos y libros de amplia difusión sobre temas fundamentales como la ética de los médicos de Stroessner, la Operación Cóndor y la OPM, la tortura y los colaboradores del régimen, así como sobre los archivos secretos del régimen dictatorial. A continuación, presentamos algunas de las profundas reflexiones de quienes entrevistamos en el marco de nuestra investigación sobre exilio, diáspora y retorno (Roniger et al., 2021).

Bernardo Cano Radil, cuya familia participó activamente en el Partido Colorado, indicó que, a pesar de que la Alianza Nacional Republicana lideró la transición, los partidarios de Stroessner vieron su regreso del exilio con reticencia. Por otra parte, Cano Radil consideró que un tercio de los Colorados se había exiliado y que el partido deseaba incorporarlos para lucir una mejor imagen de su papel durante la dictadura, algo que se le hizo evidente al participar en las negociaciones con los líderes militares de la transición. Durante el destierro, Cano Radil había estudiado filosofía política con intelectuales de izquierda en la Universidad de Córdoba y al retornar, la derecha lo consideraba un izquierdista. Sin embargo, la izquierda lo veía como un derechista, pues destacaba la importancia del desarrollo de las instituciones e insistía en el conocimiento obligatorio del español como requisito para salir de la pobreza. 
La actitud ante los lenguajes oficiales - el español y el guaraní - ha sido en Paraguay un eje divisivo fundamental de tensiones históricas, acentuadas entre los exiliados. Félix de Guarania, por ejemplo, indicaba que sólo hablaba guaraní hasta los seis años cuando fue a la escuela y comenzó a aprender español. Comunista, pasó muchos de sus años de exilio, a mediados de los años 60, trabajando como locutor de radio en Moscú, y luego en Buenos Aires, donde trabajó en una fábrica de plásticos y activó en los círculos del destierro paraguayo. Buscaba justicia escribiendo poesía y publicaba libros de poesía y cuentos bilingües en guaraní y español. En su testimonio, consideraba que uno de los mayores éxitos de la democracia era la aceptación del guaraní, la apertura con la que se enseña y se habla en el hogar y la facilidad con la que se pueden conseguir libros en esa lengua. Escribió sobre el exilio en guaraní y al día siguiente de la destitución de Stroessner sintió que, con el fin de la represión, los paraguayos habían recuperado no solo su historia, sino también la lengua nativa. De manera similar, Martín Almada indicó que el uso del idioma guaraní marca tanto la "resistencia como la identidad" de la nación. Una prueba son las memorias de Félix de Guarania Estos son mis testigos y mi testimonio (2003), que relata las violaciones a los derechos humanos perpetradas no solo bajo Stroessner, sino también durante el gobierno de Morínigo en la década de 1940.

José Carlos Rodríguez regresó a Paraguay tras trabajar junto con Luis Acevedo y Augusto Roa Bastos en el Manifiesto democrático: Una propuesta para el cambio (Acevedo et al., 1986). Rodríguez había pasado más de cuatro años en el exilio y sobre su persona pesaba aun una orden de arresto, pero decidió correr el riesgo pues creía que el público paraguayo estaría ávido de propulsar el cambio. El libro ofrecía un plan para la transición y esbozaba cambios mayores y menores que ayudarían al país en ese proceso. Al retornar, reanudó su trabajo en una ONG que había sido cerrada por la dictadura y reabierta bajo el nombre de Centro de Documentación y Estudios (CDE). El CDE ha trabajado con las comunidades indígenas, y en particular con las mujeres, y ha logrado impulsar sus causas en la constitución. Sin embargo, pronto percibió que la sociedad paraguaya no efectuaba un balance histórico. Ante los cambios y protestas bajo la naciente democracia, muchos ciudadanos idealizaban al régimen anterior, afirmando 'haber sido felices sin saberlo'; reivindicaban así la memoria de Stroessner y seguían celebrando su cumpleaños como efeméride nacional. En 2004, Rodríguez necesitó tiempo libre y se marchó a Alemania y luego a Francia para cursar estudios superiores de psicología y sociología. Regresó a Asunción meses más tarde al lograr a la distancia una visión renovada de cómo proceder en su patria. Una de las consecuencias duraderas que percibió de una dictadura que había gobernado con 
un amplio consenso de la población es el hecho de que mientras algunas figuras importantes podrían impulsar la transición, muchos paraguayos no apoyaban el retorno de los exiliados (J. C. Rodríguez, comunicación personal, 28 de agosto de 2012).

Algo similar experimentó Martín Almada al volver al Paraguay en 1990 después de largos años en Panamá y en Francia, después de haber trabajado en la UNESCO como consultor para América Latina y los países africanos de habla francesa:

Fui recibido bien y mal. Nunca olvido. Una señora de edad, una abuela me dice en guaraní: ¿Usted es el uejara (maestro) combatiente Martín Almada? Sí, abuela. Y me abraza. Después cambia de actitud y me mira, nerviosa: ¡Ajá! Ustedes que se fueron, ahora vuelven como héroes, y nosotros, que hemos quedado aquí a 'pechugar', seguimos sufriendo. (M. Almada, comunicación personal, 11 de abril de 2010)

Almada participó en la convención constitucional que incluyó un artículo novedoso referido al acceso libre a la información (el habeas data), un instrumento legal que le permitió transformarse en un "cazador de archivos". Almada tomó la iniciativa de propulsar el procedimiento legal que llevó al descubrimiento del Archivo del Terror el 22 de diciembre de 1992. Acompañado por un juez, la policía le permitió echar un primer vistazo a un depósito de 60 años (1929-1989) que incluía, según Almada, documentos que, entre otras cosas, definían la creación del Plan Cóndor. Las reacciones a su descubrimiento fueron de amor y admiración, por un lado, y de odio por parte de aquellos que añoran la época de 'paz de las sepulturas' de Stroessner.

Otro retornado fue Juan Félix Bogado Gondra, quien había sufrido persecución, siendo arrestado y torturado cuando aún era estudiante en la Facultad de Medicina en los años 60. Esa experiencia lo llevó a radicalizarse, aunque su meta había sido luchar por la justicia social en lugar de hacerlo a través de la política (F. B. Gondra, comunicación personal, 10 de abril de 2010). Habiendo completado sus estudios de medicina en Argentina, siendo de familia alemana, se radicó en Alemania de 1978 a 1986, pero no solicitó el status de refugiado. No quería vivir de la política, sino hacer política mientras se ganaba el sustento en su profesión. A su regreso al Paraguay, estableció vínculos más estrechos con el Partido Liberal Auténtico, partido que llevó a su abuelo materno a la presidencia del país. En 1989 fue nombrado secretario general del PLA, que en sólo un par de años aumentó su base de 80000 a 450000 afiliados. ${ }^{4}$ Fue desde ese lugar que

\footnotetext{
${ }^{4}$ En 2013, el número de afiliados a PLRA alcanzó 566 383, mientras que había 791014 Colorados. Sin embargo, más de 1337000 ciudadanos tienen afiliaciones múltiples ("Existen más de 1.350 .000 casos", 2015).
} 
tomó mayor conciencia de las condiciones sociales de la población y de la desigualdad que aún persistía. Decepcionado con la política y con la acomodación del liderazgo partidario, optó por volver a trabajar a Alemania para cubrir sus deudas financieras. Regresó en 2008 cuando el entonces Presidente Fernando Lugo le pidió su colaboración en el Ministerio de Salud, desde donde intentó propulsar programas sociales concretos, como parte de las nuevas redes Liberales que se movilizaron en Asunción.

Los retornados paraguayos hicieron contribuciones en aras de la democratización. Varios profesionales, miembros de ONG y expertos en humanidades y ciencias sociales unieron sus fuerzas en el foro Decidamos, un cuasi consorcio que abordó y promovió la participación ciudadana, los derechos humanos y la acción social. De igual manera, muchos participaron en el proceso político, en puestos administrativos y gubernamentales, en programas, agencias y asociaciones profesionales. Otros publicaron libros y artículos destinados a sensibilizar a la opinión pública acerca de los crímenes de Stroessner, contribuyendo a formar en los lectores una conciencia democrática y a destacar la importancia de la plena vigencia de los derechos humanos. Las ONG, en particular el Centro de Documentación y Estudios (CDE), siguen definiendo nuevas metas de reforma social. En cuanto a revertir el legado del stronismo, los esfuerzos individuales y colectivos están ofreciendo resultados significativos. Por ejemplo, Alfredo Boccia Paz, conocido por su compromiso con los derechos humanos, sabía de médicos que habían participado en sesiones de tortura u otros tratos ilegales a los prisioneros. Con otros dos psiquiatras, Carlos Portillo y Carlos Arestivo, que también habían estado en el exilio, escribió Médicos, ética y tortura en el Paraguay, que involucraba a 20 médicos en esas prácticas (Boccia Paz et al., 1992). Aunque el libro fue un éxito de ventas y los casos fueron muy difundidos, no se emprendió ninguna acción legal contra los acusados. Boccia Paz publicó asimismo Es mi informe sobre los Archivos del Terror (1994), y La década inconclusa: Historia real de la OPM (1997) sobre la policía militar, que también incluye testimonios de sobrevivientes. Autor prolífico dedicado a imprimir en la sociedad una memoria de la dictadura, escribe una columna semanal en un periódico local, aparece regularmente en programas de radio, y también publicó el Diccionario usual del stronismo (2004a). En nuestra entrevista indicó que la historia del autoritarismo en Paraguay ha sido incorporada como asignatura obligatoria en las escuelas secundarias del país, aunque no en las universidades (A. Boccia Paz, comunicación personal, 12 de abril de 2010).

De manera similar, al volver a Paraguay, Víctor Jacinto Flecha, un prolífico y respetado periodista de aguda capacidad política y analítica, concentró sus 
energías en promover un cambio de mentalidad en los paraguayos, que estaban emergiendo de lo que él definió como "un siglo de destrucción", impulsados tanto externamente por las potencias extranjeras como internamente por las élites que sofocaban cualquier signo de autonomía y pensamiento crítico (V. J. Flecha, comunicación personal, 30 de agosto de 2012). Otra iniciativa comprometida es la que desarrolló Benjamín Fernández Bogado. En 1985 se le aconsejó que abandonara el país tras recibir un premio por su documental emitido en Corea y que criticaba las condiciones en un hospital psiquiátrico. Durante la transición, como uno de las aproximadamente diez personas que vivían en el exilio, participó en la redacción de la nueva constitución; junto a algunos amigos que entonces también se encontraban en el extranjero creó la Fundación Libre. Su emisora "Radio Libre" ha sido una de las cinco más escuchadas; e imitando la sede central de la Universidad de Cornell emplazada en la ladera de un monte, invirtió en una colina de la zona la suma de dinero recibida del Premio Nacional de Literatura para construir en ella el Instituto Libre de Altos Estudios (ILAI).

Los retornados que obtuvieron su título en el exilio destacaron la importancia de instalar estudios avanzados, particularmente en áreas de ciencia y tecnología vinculadas a la base económica del país. Cuando se les preguntó sobre la situación de la educación superior, la mayoría de los entrevistados señalaron la necesidad de rediseñar la Universidad Nacional, e hicieron hincapié en el hecho de que, por el momento, los conocimientos avanzados tendrían que seguir siendo transmitidos por profesionales que poseían títulos del extranjero.

En Paraguay también hubo iniciativas editoriales con el propósito explícito de apoyar las artes y las letras. Se destacaron Juan Bautista Rivarola Matto (1933-1991), retornado, y Hugo Duarte Manzoni (1956-2013), que no abandonó Paraguay, aunque apoyó fuertemente el trabajo de los exiliados y retornados. Rivarola Matto pasó dos décadas en el exilio, regresando en 1979; fundó entonces la Editorial Napa junto con Álvaro Ayala. Llevando a la práctica la idea de la distribución popular de libros valiosos, lanzaron la iniciativa del "libro paraguayo del mes”, que produjo 42 títulos entre 1980 y 1984, entre ellos una edición bilingüe guaraní-española de cuentos populares paraguayos (De cuando Karaí Rey jugó a las escondidas) y retratos críticos de personalidades que permitieron lecturas alternativas del devenir histórico nacional. Sin embargo, Napa tuvo que cerrar debido al impacto combinado de un mercado limitado de lectores y el cierre de Paraguay a los mercados externos de libros.

La editorial de Duarte Manzoni, El Lector/Arte Nuevo, tuvo mayor continuidad. Heredero de una prensa en funcionamiento de su abuelo, y con una ubicación central para su distribución en Asunción, superó la falta de amplios 
círculos de lectores en un país más habituado a la cultura oral que a la escrita. Según su propio testimonio, el paso a la industria editorial fue motivado por el deseo de que los títulos de su propio interés personal se publicaran ampliamente, y tuvo éxito (Bittar, 2015; Manzoni, 2002). Duarte Manzoni también cooperó con la diáspora paraguaya, particularmente en Argentina. Uno de los casos en que se involucró fue el de Rubén Bareiro Saguier, quien, en Argentina democratizada, organizó una conferencia sobre derechos humanos en Paraguay y Uruguay, aún bajo un régimen dictatorial. Arte Nuevo publicó el libro de cuentos de Bareiro Saguier, El séptimo pétalo (1984) y lo introdujo de contrabando a tiempo para ser presentado durante el evento en Buenos Aires. En forma paradojal, Arte Nuevo y la industria editorial de Paraguay pasaron por momentos difíciles en la era postStroessner debido a la falta de lectores.

Por su parte, hacia el final de su vida, Roa Bastos se convirtió en asesor de una agencia gubernamental y participó en eventos educativos. Para entonces, había perdido la fe en los partidos políticos. En su lugar, estaba apoyando a los jóvenes y a las mujeres, a quienes consideraba los sectores con promesa de cambio. Ello lo llevó a promover desde 1999 a 2004 la creación de un partido feminista. En una entrevista con la periodista uruguaya Ana Ribeiro en 1998, Roa Bastos explicó su postura feminista, afirmando que las perspectivas de llevar al Paraguay hacia la democracia se basaban principalmente en la igualdad de género y en que las mujeres alcanzaran un lugar preponderante en la esfera pública:

Yo me temo que la construcción de la democracia, tal cual la soñamos -desde Rousseau hasta nuestros días- es siempre una tarea bastante difícil. Pero si vamos a entenderla como la aspiración de crear regímenes donde haya posibilidades iguales para todos, debe buscarse sobre todo que se restablezca la paridad entre el hombre y la mujer, elemento fundamental para el avance de la democracia. Tiene que haber una alianza y una transformación mutua de los géneros para que nuestras sociedades puedan funcionar con mayor vitalidad.

[...] Yo defiendo siempre a la mujer. Yo soy partidario de la mujer como el ser por antonomasia superior en la creación humana. [...] La defiendo además porque la mujer es la protagonista absoluta de la historia del Paraguay. He visto en las sencillas mujeres de pueblo, en mi propia madre (para mí el ejemplo mayor), el poder espiritual y físico, la resistencia, la tenacidad, la paciencia, la capacidad de esperar y de esperanza que tiene como superior a la mujer frente al hombre. (Ribeiro, 1999)

Carlos Pérez Cáceres, del diario Últimas Noticias, coincidió con que el regreso de Roa Bastos fue importante. Según él, la prensa le abrió sus puertas y la gente lo veía como "el intelectual que podía abordar cualquier asunto", aunque siempre se mantuvo cauteloso al hablar de algunos temas (C. Pérez Cáceres, comunicación personal, 29 de agosto de 2012). Hubo, por supuesto, otros poetas y escritores que participaron en eventos políticos pero carecían de su prestigio 
internacional. Sin embargo, a su regreso, Roa Bastos confesó que ya no sabía escribir textos literarios a la altura de aquellos que escribió en el exilio (Pinto, 2008). Además, a su regreso, todas sus energías se orientaron a intentar desenmarañar el persistente legado del autoritarismo, el faccionalismo y la falta de pensamiento crítico. Aunque otros buscaban inspiración en él, se volvió pesimista respecto a su capacidad de impulsar el cambio necesario en la sociedad y la política paraguaya. ${ }^{5}$

Ticio Escobar, reconocido antropólogo y Ministro de Cultura en el gobierno de Lugo, analizó el impacto de la dictadura de Stroessner y cuáles han sido sus secuelas. Entre las prioridades que presentaron los trabajadores de la cultura en la naciente democracia se encontraban: centralizar la cultura, después de décadas de marginalización durante la dictadura; promover el trabajo crítico y creativo al conjunto de la sociedad, y fomentar la profesionalidad del sector de la cultura. Lográndolo, creía, la cultura podría llegar a desempeñar un papel importante en la democratización del país (Escobar, 1992).

Otro escritor paraguayo de reconocimiento internacional fue el ya citado Rubén Bareiro Saguier (1930-2014), quien vivió en Francia de 1972 a 1989 después de haber sido encarcelado y torturado. ${ }^{6}$ Bareiro Saguier participó activamente en la convención constitucional y posteriormente fue embajador de Paraguay en París (1995-2003). Afiliado al PLRA, adquirió su educación política de su padre, quien también sufrió persecución y exilio en Argentina. Bareiro Saguier sentía que los nacidos en el exilio no eran considerados paraguayos, sino "hijos de un exiliado"; sin embargo, agregó, el campo intelectual no estaba tan ásperamente dividido como en la Argentina. Como prueba, mencionó una revista literaria y cultural que incluía grupos que no compartían las mismas creencias políticas. Más conocido como narrador, Bareiro Saguier no abandonó la poesía - aunque siempre en español, similar al caso de otros escritores paraguayos, si bien el guaraní se cuela con naturalidad en sus textos. Conversando con nosotros, manifestó que desde su regreso, además de escribir para la prensa local e interactuar con los jóvenes, su contribución más importante fue su trabajo sobre la Constitución de 1992 y su participación en la revisión final (R. Bareiro Saguier, comunicación personal, 31 de agosto de 2012).

\footnotetext{
${ }^{5}$ Compare la entrevista a su regreso final en 1996 con entrevistas posteriores. Ver Pinto, 2008; "Roa Bastos: del exilio a la ficción", 2005.

${ }^{6}$ Un dossier sobre su caso, incluyendo su propio testimonio, sus poemas, su "Misa por un continente," con una introducción del premio Nobel de Literatura Miguel Ángel Asturias, y cartas de la campaña internacional por su liberación, pueden verse en Saguier, 1973.
} 
La incorporación de las lecciones aprendidas durante el exilio ha sido una lucha constante entre los retornados y los que permanecieron en el país. El testimonio de Alejandro Méndez Mazó alude a ello (comunicación personal, 14 de abril de 2010). Después de un atentado contra la vida de su padre, llegó a Buenos Aires a la edad de 13 años para vivir en un exilio que duró 22 años. Al estar fuera de Paraguay, adquirió una educación y una visión crítica de la que siguen careciendo miembros de su generación que permanecieron en el país. Sin embargo, se mantuvo conectado con la comunidad paraguaya en la diáspora y de hecho se sintió vivir en un enclave étnico. El regreso le fue muy difícil pues según él, los paraguayos aceptaban a la gente y toleraban a los extranjeros, pero no perdonaban a un paraguayo con 'tendencias extranjeras'. Siempre que un retornado hacía una propuesta, la respuesta era que no era aplicable y cínica o irónicamente se sugería lo extraño que un paraguayo pensara en ello.

Méndez Mazó continuó impulsando a todos los partidos a que incluyeran el 'desexilio' como parte de la agenda política, social y cultural del Paraguay. Con ese fin ha realizado actividades culturales en el país y sigue manteniendo un estrecho contacto con los paraguayos que optaron por no regresar. Tras la destitución del presidente Lugo, Méndez Mazó ha seguido comprometido con muchos de los mismos objetivos nacionales a través de organizaciones de la sociedad civil, abogando para que los paraguayos en el exilio sean tenidos en cuenta en todas las actividades culturales. Miembro del Partido Revolucionario Febrerista desde 1985, fue varias veces candidato a cargos públicos; sus opiniones políticas se transmiten a través de la columna cultural de la publicación mensual de su partido, El Pueblo. Si bien la administración cultural y la interpretación son sus credenciales más visibles, también es compositor, periodista, una personalidad de la radio y activista social y político en temas ambientales. Sin embargo, a pesar de un destacado historial de nombres de interesados en las artes y en otros campos, dice que "el destierro aún no ha llegado a su fin".?

\section{LA COMISIÓN DE VERDAD Y JUSTICIA}

Como consecuencia de las reuniones celebradas en 2008 entre el Presidente Fernando Lugo y Monseñor Mario Melanio Medina, titular de la Comisión de Verdad y Justicia (CVJ), se estableció en 2009 un programa de protección de

\footnotetext{
${ }^{7}$ El 17 de junio de 2010, Mario Ferreiro, la personalidad de radio más conocida en Paraguay, que considera que Méndez Mazó fue "el primero en hablar de 'desexilio' en Paraguay", lo entrevistó para obtener su opinión sobre una decisión entonces polémica de incorporar a jugadores considerados "extranjeros", por haber sido criados en el exilio, dentro del equipo nacional de fútbol.
} 
los derechos humanos y de reparación de los daños causados a los exiliados en la diáspora. El mismo se llevó a cabo en el marco de la Defensoría del Pueblo de Paraguay, bajo el nombre de Dirección General de Verdad, Justicia y Reparación o DGVJR (Resolución 179/09). Yudith Rolón Jaquet, miembro distinguido de la $\mathrm{CVJ}$, fue nombrada directora de esa agencia y se encargó de coordinar las actividades de las otras agencias estatales con las ONG que trabajaban por los derechos humanos, de celebrar audiencias públicas sobre el tema y de presentar informes anuales sobre actividades y logros (Arellano, 2012). El Estado creó la DGVJR para implementar las recomendaciones de la CVJ y generar un programa integral para responder a las necesidades de las víctimas de violaciones a los derechos humanos. El programa fue elaborado en consenso con las víctimas en audiencias públicas. Las actividades incluían compensaciones monetarias tanto para los que regresaban del exilio como para los que se quedaban en el extranjero. Esto se consideró una continuación natural del trabajo realizado por la CVJ que terminó su mandato cuando presentó su informe final, Anive Hagua Oiko, a las tres ramas del Estado en agosto de 2008 (Dirección General de Verdad, Justicia y Reparación; Defensoría del Pueblo, 2009).

Básicamente, la DGVJR fue creada para implementar las propuestas de la CVJ: preservar el material de los archivos, continuar la investigación sobre el historial de violaciones a los derechos humanos, coordinar programas con la ONU y otras organizaciones internacionales que trabajan en derechos humanos, promover programas educativos y luchar contra la discriminación, promoviendo al mismo tiempo la práctica de los derechos humanos. Las recomendaciones 65 , 66, 67, 75 y 168 de la CVJ se referían a la reparación a las víctimas del exilio (Comisión de Verdad y Justicia, 2008). La R65 abordaba la necesidad de fortalecer la relación entre Paraguay y sus exiliados en el exterior. La R66 señalaba la necesidad de acuerdos entre Paraguay y los Estados anfitriones donde aún residían los exiliados. Aquí, el tema del voto de los paraguayos en el extranjero se hizo relevante. La R67 se centró en el proceso de reintegración familiar y el retorno al Paraguay. Debido a la duración de la dictadura y, en consecuencia, del exilio, este tema ha sido muy difícil de desarrollar. La R75 hablaba de devolver a los exiliados su patrimonio familiar y, sobre todo, los bienes inmuebles que les habían sido arrebatados por la fuerza. La cantidad de tierras expropiadas por individuos asociados con la dictadura de Stroessner (conocidas como 'tierras mal habidas') es bastante extensa, y el problema es particularmente difícil de resolver ya que las propiedades han cambiado de manos sucesivamente en forma legal. Ello se complica aún más por el hecho de que muchos migrantes y propietarios de tierras de nacionalidad brasileña adquirieron a precios bastante bajos tierras que habían sido propiedad de exiliados y migrantes. La R168 trata la inclusión 
social y la política del exilio, exigiendo una reforma constitucional para otorgar el derecho al voto a los paraguayos en el exterior.

\section{LA DIÁSPORA PARAGUAYA Y EL DERECHO AL VOTO}

El gran número de exiliados, expatriados y migrantes paraguayos planteó interrogantes acerca de los derechos que podrían obtener al regresar. En primer lugar, si se reconocerían los principios básicos de la ciudadanía para las parejas y los hijos de emigrantes y exiliados que no nacieron en el país de origen, o a favor de quienes no habían adquirido la nacionalidad de sus padres, o bien de aquellos que regresaran con familiares que no tuvieran ningún vínculo previo con el país natal. Asimismo, al igual que en otras latitudes, se planteó la pregunta de la reconexión con la diáspora y en forma especial, si se conferirían derechos políticos a los connacionales que decidieran permanecer en el extranjero (de Haas, 2006; Sinatti \& Horst, 2015).

El derecho al voto para el gran número de paraguayos residentes en el exterior fue uno de los temas debatidos por la Asamblea Constituyente en 19911992. La fuerza política dominante, el Partido Colorado que tenía 122 de los 198 representantes, impuso un requisito de residencia. A fin de preservar su control político, los Colorados actuaron presumiendo que la mayoría de los residentes en el exterior habían huido del Paraguay cuando el partido constituía la base de poder del régimen de Stroessner y que, por tanto, el voto de los residentes en la diáspora podría inclinar la balanza en su contra. Vale decir, la ANR temía que el PLRA pudiera capitalizar los votos de la diáspora. Esto condujo a una gran controversia dentro de los partidos políticos y en la sociedad civil, generando opiniones contradictorias e incluso divisiones en las fuerzas políticas. Los militantes del PLRA en la diáspora se opusieron a la decisión de exclusión y continuaron promoviendo la necesidad de un referéndum en años posteriores, al igual que los militantes residentes en el Paraguay. En forma convergente, los militantes del Partido Colorado residentes en Argentina criticaron la posición de su partido en la Asamblea Constituyente, afirmando exigir la posibilidad de ejercer plenamente su ciudadanía mediante el voto ("Carta de la Seccional Colorada", 1992).

Once asociaciones de paraguayos en el exterior mantuvieron un activismo político, especialmente después de la destitución del Presidente Fernando Lugo Méndez, y exigieron que el gobierno se ocupe de sus problemas y promueva una mayor inclusión de la diáspora (Paraguay Resiste, 2013). Los Liberales han sido uno de los principales actores políticos a favor de la enmienda constitucional. En 2010, el bloque liberal del Parlamento lideró la propuesta de modificación del 
artículo constitucional 120 que excluía a la diáspora del ejercicio de derechos electorales. Un año después, por primera vez después de muchos años de hegemonía del Partido Colorado, el PLRA compartió el poder ejecutivo encabezado por el presidente Lugo, junto a Federico Franco como vicepresidente. Además, el PLRA tuvo un peso significativo en la legislatura, posicionándose sólo ligeramente por detrás de los Colorados en fuerza numérica. A lo largo de los años, el PLRA había aumentado el número de afiliados en Buenos Aires y los numerosos simpatizantes se mostraron optimistas sobre sus posibilidades de ganar la presidencia en las elecciones generales previstas para 2013. El Partido Colorado también había ampliado su base de afiliados y su influencia entre las asociaciones paraguayas en Argentina, estableciendo relaciones más sólidas con los políticos argentinos.

No sorprende, por tanto, que las asociaciones de exiliados y emigrantes, principalmente en Buenos Aires, tomaran la iniciativa de lograr la enmienda al Artículo 120 en ambas cámaras legislativas (Halpern, 2003). El 3 de septiembre de 2011 Buenos Aires fue sede de la reunión de representantes de la diáspora paraguaya en la que se lanzó oficialmente la Coordinadora por el Sí, un foro a favor de lograr el voto para los residentes en el exterior. El evento, organizado en el emblemático Club Deportivo Paraguayo, contó con la participación de un amplio espectro de organizaciones sociales y políticas, entre ellas: la Asociación Paraguaya de Trabajadores en Argentina (APTRA), el Congreso Permanente de la Migración Paraguaya en Argentina (Copempara), la Confederación Nacional de Trabajadores (CNT), el Encuentro Pastoral Paraguayo en Argentina (EPPA), la Federación de Paraguayos en Argentina (Fepara), el Frente Guasu, la ANR, el PLRA, el Partido Comunista Paraguayo (PCP), el Partido Revolucionario Febrerista (PRF) y el Partido Tekojoja.

El papel crucial de la diáspora en este proceso fue el resultado de muchos años de activismo político, reforzado por los mecanismos legales de integración democrática y dinámica migratoria transnacional reconocidos en el Mercosur. Gerardo Halpern llamó la atención sobre estos factores:

El desarrollo histórico de las organizaciones paraguayas en el exterior en pos de la adquisición de derechos se basó, en primer lugar, en la vitalidad de las organizaciones sociales de migrantes y exiliados que luchan contra la discriminación en la Argentina, y al mismo tiempo en el uso táctico simultáneo de los instrumentos jurídicos que Paraguay había adoptado al convertirse en miembro del Mercosur en los años noventa. Estas dimensiones organizativas e identitarias permitían no sólo luchar contra la dictadura de Stroessner desde más allá de las fronteras territoriales paraguayas sino también hacer frente a ciertas formas de exclusión durante la transición. Fue esa politización la que dio peso histórico y cultural al proceso político de convocatoria al referéndum de octubre de 2010. (Halpern \& López, 2011) 
En su calidad de miembro del Mercosur, Paraguay había firmado y aprobado acuerdos multilaterales que abarcaban la residencia y la circulación de los ciudadanos dentro de los países del Mercosur. A pesar de privar a los paraguayos en el extranjero de ejercer su derecho al voto, había reconocido los derechos de los migrantes en el marco de la Convención Sudamericana sobre Migración, e incluso había firmado en septiembre de 2000 la 'Convención Internacional sobre la protección de los derechos de todos los trabajadores migratorios y de sus familias'. Sin embargo, hasta la aprobación de la enmienda al artículo 120 en octubre de 2011, Paraguay negaba el derecho al voto a quienes vivían en la diáspora, si bien reconocía los derechos de los trabajadores migrantes de los países del Mercosur a participar en la vida pública de sus Estados de origen, conforme al artículo 41 de la Convención Internacional. En octubre de 2011 un referéndum popular modificó la Constitución de 1992 y aprobó el voto de los paraguayos en el exterior. Cabe señalar que el porcentaje de participación en ese referéndum fue bajo, aunque cuando casi cuatro quintas partes de quienes votaron se pronunciaron a favor del cambio ("Ejecutivo oficializa el voto", 2011). El ausentismo se atribuyó a factores como la escasa publicidad y el clima de desmovilización creado por la amenaza de un boicot difundido por los operadores del transporte urbano, aunque no se descarta la indiferencia y la apatía cívica. El voto por el Sí fue impulsado por los residentes en el exterior, principalmente en la diáspora argentina (Elecciones Paraguay, s.f.; Misión de Observación Electoral de la Unión Europea, 2013). Sin embargo, para las elecciones generales siguientes, en 2013 nuevamente sólo 21981 ciudadanos inscriptos residentes en el exterior votaron, lo que representó el 4,1\% de todos los residentes en Argentina y sólo el 0,86\% del total de los votos emitidos.

\section{CONCLUSIONES}

El exilio paraguayo sobresale por su duración y magnitud. En 2011 se estimaba que el número de paraguayos en la diáspora excedía los 777 000, de los cuales más de 550000 residían en la Argentina, 135000 en España y cerca de 40000 en Brasil (Odone, 2011). La dictadura, que duró décadas, dio lugar a exilios masivos, expatriaciones y migraciones que afectaron a todas las clases y sectores sociales, entre los que se encontraban intelectuales e importantes representantes de la clase política.

A pesar de que la mayoría de los desterrados paraguayos se habían radicado en los países limítrofes y que el Paraguay tuviera la mayor proporción de migrantes en el Cono Sur, el país no ha organizado una campaña cuantitativa o cualitativa para repatriar a sus migrantes. Dada la duración y magnitud del exilio paraguayo, existió un flujo sostenido de intercambios entre la diáspora y el país de origen; sin 
embargo, el rechazo a los que regresaban del exilio no se daba solo en casos aislados, especialmente cuando tenía lugar en un contexto económico problemático y los retornantes potenciales o concretos pertenecían a fuerzas políticas opuestas.

El retorno paraguayo fue, pues, selectivo y debió enfrentar la falta de una decisiva voluntad política para elaborar políticas de retorno, ello a pesar de que, durante la transición y aun con limitados recursos estatales, Paraguay contaba con mejores perspectivas económicas que otros países como la Argentina o Uruguay, que habían transitado a la democracia en tiempos de la década 'perdida' de los 1980. Además, en contraposición a Argentina y Uruguay, donde el retorno fue mayormente un fenómeno postdictatorial, en Paraguay -al igual que en Chile-el retorno del exilio había comenzado ya durante la dictadura. En el caso paraguayo, lo que primó fue la determinación individual de retornar más que la voluntad de la clase política de adoptar normas relativamente amplias de retorno y facilitar que los retornados promovieran una cultura pública democrática. La falta de incentivos y facilidades para el retorno, así como las escasas oportunidades económicas y de empleo, explican que muchos de ellos permanecieran fuera del territorio nacional. Quienes regresaron debieron enfrentar un proceso arduo de 'desexilio'. Superando rechazos e indiferencias, intentaron llevar adelante iniciativas y contribuir a debates orientados a democratizar la cultura paraguaya. Aunque importantes, las iniciativas culturales produjeron solo logros parciales, no consiguiendo desarticular los enclaves autoritarios que la larga dictadura de Stroessner impuso en Paraguay.

Finalmente, el reconocimiento político de la diáspora paraguaya fue patentizado por el referéndum constitucional que confiere el derecho al voto a los paraguayos en el exterior, pese a la escasa participación en las elecciones de 2013.

\section{REFERENCIAS BIBLIOGRÁFICAS}

Acevedo, L., Rodríguez, J. C., \& Roa Bastos, A. (1986). Manifiesto democrático: Una propuesta para el cambio. Araverá.

Arellano, D. (2004). Regreso en armas: Movimiento 14 de mayo para la Liberación del Paraguay. Novapolis, (8), 41-59.

Arellano, D. (2012). Reparar lo irreparable: Las víctimas de exilio frente a las políticas de reparación social en Paraguay. http://sedici.unlp.edu.ar/bitstream/handle/10915/32179/Documento_completo.pdf

Ayala, M. (2014). Los exiliados argentinos en Venezuela: Solidaridad, denuncia y construcción de redes regionales de Derechos Humanos (1976-1981). In S. Jensen \& S. Lastra (eds.), Exilios, militancia y represión: Nuevas fuentes y nuevos abordajes de los destierros de la Argentina de los años setenta (pp. 121-156). EDULP. 
Bareiro Saguier, R. (1973). Rubén Bareiro Saguier. Hispamérica, 2(4/5), 73-101.

Bittar, C. (2015). Hugo, in memoriam. http://bittarb2.blogspot.co.il/2013/01/hugo.html

Boccia Paz, A. (1994). Es mi informe: Los archivos secretos de la policía de Stroessner. Centro de Documentación y Estudios.

Boccia Paz, A. (1997). La década inconclusa. La historia real de la OPM. El Lector.

Boccia Paz, A. (2004a). Diccionario usual del stronismo. Servilibro.

Boccia Paz, A. (2004b). OPM: La profecía autocumplida. Novapolis, (8), 91-106.

Boccia Paz, A. (2014). Goibirú, la odisea del insumiso. Servilibro.

Boccia Paz, A., Portillo, C., \& Arestivo, C. (1992). Médicos, ética y tortura en el Paraguay. RP Ediciones.

Carta de la Seccional Colorada. (1992, 13 de mayo). Última Hora, 8.

Comisión de Verdad y Justicia. (2008). Informe Final. CVJ.

Crónica sobre el retorno de los exiliados al Paraguay. (1984). Revista Ñe-Engatú, 2(12).

de Haas, H. (2006). Engaging diasporas: How governments and development agencies can support diaspora involvement in the development of origin countries. Oxfam Novib.

Dinges, J. (2005). The Condor Years. Free Press.

Dirección General de Verdad, Justicia y Reparación; Defensoría del Pueblo. (2009). Antecedentes de la Creación de la Comisión de Verdad, Justicia y Reparación: Resolución 179/09. www.verdadyjusticia-dp.gov.py.

Ejecutivo oficializa el voto de los paraguayos en el exterior. (2011, 8 de noviembre). Última Hora. http://www.ultimahora.com/ejecutivo-oficializa-el-voto-los-paraguayos-el-exteriorn479022.html

Elecciones Paraguay. (s.f.). Elecciones en Paraguay: Como votan los Paraguayos en el extranjero.

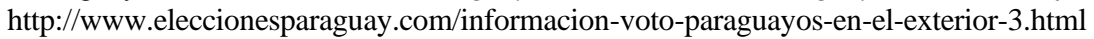

Escobar, T. (1992). Textos varios sobre cultura, transición y modernidad. Agencia Española de Cooperación Internacional, Centro Cultural Español Juan de Salazar.

Existen más de 1.350 .000 casos de múltiples afiliaciones en ANR y PLRA. (2015, 15 de junio). $A B C$. https://www.abc.com.py/edicion-impresa/politica/existen-mas-de-1350000-casos-de-multiples-afiliaciones-en-anr-y-plra-1377696.html

Halpern, G., \& López, M. (2011). Referéndum y enmienda constitucional: Modificación del artículo 120 de la Constitución paraguaya. In G. Halpern (ed.), Migrantes: Perspectivas (críticas) en torno a los procesos migratorios del Paraguay (pp. 372-373). Ape Paraguay.

Halpern, G. (2003). Exiliar a los exiliados: Acerca del derecho al voto de los paraguayos en el exterior. In L. Calderón Chelius (ed.), Votar en la distancia: La extensión de los derechos políticos a migrantes, experiencias comparadas (pp. 345-386). Instituto Mora.

Lewis, P. H. (1968). The politics of exile: Paraguay's Febrerista Party. University of North Carolina Press.

Manzoni, H. D. (2002). La condición editorial. América Sin Nombre, (4), 23-27. 
https://doi.org/10.14198/AMESN2002.4.05

Misión de observación electoral de la Unión Europea. (2013). Misión de observación electoral de la Unión Europea en Paraguay, Elecciones Generales. http://www.eueom.eu/files/pressreleases/other/informe-final-paraguay-2013_es.pdf

Moyas Cobos, E. A. (ed.). (1989). Exilio y resistencia: Los movimientos políticos de exiliados paraguayos en Argentina. Declaraciones y crónicas desde 1983 hasta la caída de Stroessner. Alberto Kleiner.

Odone, H. (ed.). (2011). Perfil migratorio de Paraguay 2011. OIM.

Paraguay Resiste. (2013, agosto). Comunicado a la opinión pública de las organizaciones de Paraguayos y Paraguayas en el exterior. http://paraguayresiste.com/comunicado-a-la-opinionpublica-de-las-organizaciones-de-paraguayos-y-paraguayas-en-el-exterior

Pecci, A. (1997). Roa Bastos: Vida, obra y pensamiento. UniNorte.

Pinto, D. (2008, 5 de abril). Entrevista a Augusto Roa Bastos II: Palabras de un hombre de América. http://nuevoperiodismopuntocom.blogspot.co.il/2008/04/entrevista-augusto-roa-bastosii.html

Roa Bastos, A. (1986). Carta abierta al Pueblo Paraguayo. http://fundacionroabastos.org/obras/ensayos/Carta\%20Abierta\%20al\%20Pueblo\%20 Paraguayo.pdf

Roa Bastos: del exilio a la ficción. (2005, 27 de abril). BBC Mundo. http://news.bbc.co.uk/hi/spanish/misc/newsid_4489000/4489387.stm

Ribeiro, A. (1999, 8 de enero). El supremo compilador. http://letras-uruguay.espaciolatino.com/ribeiro_ana/con_roa_bastos.htm

Roniger, L. (2010). U.S. hemispheric hegemony and the descent into genocidal practices in Latin America. In M. Esparza, D. Feierstein \& H Huttenbach (eds.), State violence and genocide in Latin America: The Cold War years (pp. 23-43). Routledge.

Roniger, L., Senkman, L., Sosnowski, S., Sznajder, M. (2021). Exilio, diáspora y retorno: Transformaciones e impactos culturales en Argentina, Chile, Paraguay y Uruguay. Eudeba.

Sánchez, M. A. (2011). Destierro, desplazamiento forzado y exilio político de paraguayos en la Argentina 1954-1983: La represión transnacional bajo el régimen de Stroessner. Pacarina del Sur. http://pacarinadelsur.com/home/abordajes-y-contiendas/320-destierrodesplazamiento-forzado-y-exilio-politico-de-paraguayos-en-la-argentina-1954-1983-larepresion-transnacional-bajo-el-regimen-de-stroessner

Secretaría de Desarrollo Para Repatriados y Refugiados Connacionales. (s.f.). https://www.repatriados.gov.py/

Sinatti, G., \& Horst, C. (2015). Migrants as agents of development: Diaspora engagement discourse and practice in Europe. Ethnicities, 15(1), 134-152. https://doi.org/10.1177/1468796814530120

Souchaud, S. (2010). Aspectos políticos de la inmigración y emigración internacionales en Paraguay al principio del siglo XXI. In C. Zurbriggen \& L. Mondol (eds.), Estado actual y perspectivas de las políticas migratorias en el MERCOSUR (pp. 131-152). FLACSO. 